\title{
Experimental and analytical studies of fatigue crack growth in peened after skimmed friction stir welded joint of 2024-T351 Al alloy
}

\begin{abstract}
The present work studies the crack behavior along the surface of the friction stir welded (FSW) joint of 2024-T351 aluminum alloy. The surface engineering of shot peening and skimming are used to enhance the fracture characteristics of the joint. Then multiple crack initiation is detected within FSW zones by scanning electron microscopy, while plastic replication technique is used to monitor the crack propagation. The variation of residual stress is measured (using hole drilling technique) as well as hardness characteristic (using standard method of Vicker) to study the fatigue life of the FSW by two models of Pearson and Nicholls, incorporating crack closure and stress relaxation.
\end{abstract}

Keyword: Fatigue life; Crack growth; Friction stir welding; Pearson model; Nicholls model 